\title{
VALIDITAS RASIO NEUTROFIL LIMFOSIT PADA APENDISITIS KOMPLIKATA DI RSUP SANGLAH DENPASAR
}

\author{
Dewi Prima Christian', I Gede Suwedagatha ${ }^{2}$, Nyoman Golden ${ }^{3}$, I Ketut Wiargitha ${ }^{2}$ \\ ${ }^{1}$ Program Pendidikan Dokter Spesialis Bedah, Fakultas Kedokteran Universitas Udayana, Denpasar, Indonesia. \\ Korespondensi: oniel_od@yahoo.com \\ ${ }^{2}$ Subbagian Bedah Trauma dan Bedah Akut, Bagian Ilmu Bedah Fakultas Kedokteran Universitas \\ Udayana/Rumah Sakit Umum Pusat Sanglah, Denpasar, Indonesia. \\ ${ }^{3}$ Subbagian Bedah Saraf, Bagian Ilmu Bedah Fakultas Kedokteran Universitas Udayana/Rumah Sakit Umum \\ Pusat Sanglah, Denpasar, Indonesia.
}

\begin{abstract}
ABSTRAK
Tujuan: untuk mengetahui validitas rasio neutrofil limfosit (RNL) pada apendisitis komplikata. Metode: penelitian dilakukan secara observasional analitik dengan menggunakan desain studi kohort dengan mengambil sampel penderita apendisitis akut yang menjalani apendisektomi di RSUP Sanglah Denpasar, periode Oktober-Desember 2015. Data dikelompokkan menjadi dua kelompok, yaitu RNL dengan cut of point $>5$ dan RNL dengan cut of point $\leq 5$ dan kemudian disesuaikan dengan temuan pemeriksaan histopatologi anatomi sebagai standar baku emas, komplikata dan non-komplikata. Data tersebut kemudian dianalisis dengan analisis statistik deskriptif, analisis kurva ROC, dan uji diagnostik. Hasil: pada penelitian ini diperoleh 62 sampel, dengan median umur 23 tahun, 32 orang penderita lakilaki, 30 orang penderita perempuan, 28 apendisitis non-komplikata, dan 34 apendisitis komplikata. Dari area under curve ROC 0,6229 dengan 95\% CI didapatkan cut of point RNL >5 pada apendisitis komplikata, RNL $\leq 5$ pada apendisitis non-komplikata. Uji diagnostik didapatkan nilai sensitivitas $85,3 \%$, spesifisitas 39,3\%, dan tingkat akurasi $64,5 \%$. Simpulan: RNL merupakan tolak ukur sederhana yang lebih baik untuk meramalkan apendisitis akut dibandingkan dengan penilaian Alvarado Score dan USG abdomen serta valid untuk membedakan apendisitis komplikata dan non-komplikata melalui cut of point RNL.
\end{abstract}

Kata kunci: apendisitis akut, apendisitis komplikata, apendisitis non-komplikata, rasio neutrofil limfosit (RNL).

\section{THE VALIDITY NEUTROPHIL LYMPHOCYTE RATIO OF COMPLICATED APPENDICITIS IN SANGLAH GENERAL HOSPITAL DENPASAR}

\author{
Dewi Prima Christian' ${ }^{1}$, I Gede Suwedagatha ${ }^{2}$, Nyoman Golden ${ }^{3}$, I Ketut Wiargitha ${ }^{2}$ \\ ${ }^{1}$ Genaral Surgery Training Programme, Faculty of Medicine, Udayana University, Sanglah General Hospital, \\ Denpasar, Indonesia. \\ ${ }^{2}$ Trauma and Acute Care Surgery Division, Surgery Department, Faculty of Medicine Udayana University, \\ Sanglah General Hospital, Denpasar, Indonesia. \\ ${ }^{3}$ Neurosurgery Division, Surgery Department, Faculty of Medicine Udayana University, Sanglah General \\ Hospital, Denpasar, Indonesia.
}

\begin{abstract}
Objective: The purpose of this study is to know the validity neutrophil lymphocyte ratio (NLR) of complicated appendicitis. Methods: A cohort study with observational analytic was performed on patients whom diagnosed for acute appendicitis those undergoing appendectomy from October December 2015. The data were into two grouped according to cut of point NLR $>5$ and NLR $\leq 5$. This group was associated with postoperative histopathological examination as a gold standard, complicated
\end{abstract}

1 | Jurnal Bedah Nasional 
and uncomplicated appendicitis. This study was analysed with descriptive analysis, ROC curve and diagnostic test. Results: from total 62 sample, median age 23 years old, 32 males, 30 females, 28 uncomplicated appendicitis, 34 complicated appendicitis. The area under curve ROC 0.6229 with $95 \%$ CI got the cut of point NLR were $>5$ associated with complicated appendicitis and NLR $\leq 5$ assosiated with uncomplicated appendicitis. The results were sensitivity $85.3 \%$, spesificity $39.3 \%$, and accuracy rate $64.5 \%$. Conclusion: Based on this study it can be concluded, that NLR is the better marker and simple for diagnosis rather than Alvarado Score and USG, and valid to differentiate between complicated and uncomplicated appendicitis through cut of point NLR.

Keywords: acute appendicitis, complicated appendicitis, uncomplicated appendicitis, neutrophil lymphocyte ratio (NLR).

\section{PENDAHULUAN}

Apendisitis akut adalah peradangan dari apendiks vermiformis dan merupakan kasus pembedahan darurat nyeri perut akut sekitar $10 \%$ terbanyak, terjadi pada semua golongan usia terutama usia 20-30 tahun dengan angka insiden paling banyak ditemukan pada laki-laki dibandingkan dengan perempuan 1,4: $1{ }^{1}$ Di Amerika Serikat angka insiden apendisitis akut adalah 1 per 1000 orang. Risiko seseorang terkena apendisitis akut sepanjang hidupnya adalah sekitar $6-9 \% .^{2}$

Kasus apendisitis akut memerlukan penanganan yang tepat serta penegakan diagnosis yang cepat. Keterlambatan diagnosis akan berdampak pada komplikasi yang akan terjadi, seperti gangrenosa, perforasi bahkan dapat terjadi peritonitis generalisata. Morbiditas dan mortalitas akan meningkat sesuai dengan peningkatan komplikasi yang ditemukan. ${ }^{3}$ Apendisitis komplikata dapat terjadi oleh karena beberapa faktor baik dalam kecepatan penegakan diagnosa atau keterlambatan pasien akibat kurangnya pengetahuan. Beberapa pasien yang menunjukkan gejala dan tanda apendisitis yang tidak khas dapat menyebabkan kesalahan dalam diagnosis dan keterlambatan dalam hal penanganannya. Beberapa pasien yang datang dengan gejala dan tanda apendisitis yang tidak khas akan dilakukan pemeriksaan lanjutan seperti USG abdomen yang akan memakan waktu lebih lama dalam penegakan diagnosis serta memerlukan biaya yang lebih mahal. Pemeriksaan dengan USG memiliki kelemahan, yakni masih bersifat subjektif (operator dependent), tidak banyak memberikan informasi yang akurat serta tidak dapat membedakan apendisitis komplikata dan non-komplikata. Pemeriksaan lainnya yaitu menilai Alvarado Score, namun sistem skoring ini pun masih memiliki kelemahan yaitu bersifat subyektif dan tidak bisa membedakan apendisitis non-komplikata dan komplikata. ${ }^{4}$

Salah satu pemeriksaan lainnya pada pasien apendisitis adalah pemeriksaan laboratorium dengan menilai leukosit dan juga neutrofil. Pemeriksaan ini merupakan tes yang sensitif untuk apendisitis tetapi memiliki sensitivitas yang rendah untuk diagnostik apendisitis dan belum bisa dipakai untuk membedakan apendisitis komplikata dan non-komplikata. Adapun pemeriksaan lainnya yang terbukti memiliki sensitivitas lebih tinggi untuk mendiagnosis apendisitis yaitu menilai angka neutrofil dan limfosit kemudian dirasiokan. Hasil rasio neutrofil limfosit 
yang tinggi akan menunjukkan inflamasi yang berat seperti apendisitis komplikata. ${ }^{5}$

Berdasarkan permasalahan di atas, peneliti ingin meneliti lebih lanjut mengenai validitas dari rasio neutrofil limfosit pada apendisitis komplikata. Keuntungan dari pemeriksaan ini yaitu pemeriksaan bersifat obyektif, murah, cepat dan tersedia di semua rumah sakit. Penelitian ini belum pernah dilakukan sebelumnya di RSUP Sanglah Denpasar dan selama ini parameter pemeriksaan lanjutan pada apendisitis akut di RSUP Sanglah Denpasar hanya dengan berdasarkan hasil labotarorium rutin, Alvarado Score, dan USG abdomen.

\section{METODE}

Penelitian ini merupakan penelitian uji diagnostik observasional analitik dengan menggunakan desain studi kohort. Subyek penelitian saat awal dipisahkan berdasarkan cut of point neutrofil limfosit $>5$ dan $\leq 5$ yang diadopsi dari penelitian Kahramanca. ${ }^{4}$ Penilaian neutrofil limfosit tersebut diambil dari sampel darah penderita. Kemudian dari hasil tersebut di observasi melalui operasi apakah hasil tersebut merupakan apendisitis komplikata atau nonkomplikata. Tempat penelitian adalah di instalasi rawat darurat (IRD) bedah RSUP Sanglah Denpasar Bali. Waktu penelitian dilaksanakan pada bulan Oktober sampai Desember tahun 2015. Adapun kriteria inklusi adalah semua pasien apendisitis akut yang datang ke IRD bedah RSUP Sanglah Denpasar dari bulan Oktober sampai Desember tahun 2015 dan menjalani operasi. Kriteria eksklusi diantaranya penderita menolak ikut serta dalam penelitian, penderita dengan komorbid diabetes melitus, infeksi kronis, keganasan, dan imunokompromise, pasien yang sudah mendapatkan terapi antibiotik dan analgetik sebelumnya, dan pasien dengan kehamilan.

\section{HASIL}

Telah dilakukan uji diagnostik rasio neutrofil limfosit terhadap 62 sampel penderita apendisitis akut dan telah menjalani operasi apendisektomi selama bulan Oktober hingga Desember 2015 dengan hasil histopatologi sebagai standar baku emas.

Dari 62 penderita apendisitis akut tersebut, berdasarkan umur didapatkan nilai median 23 tahun dan interquartile range (IQR) 15 tahun, yang mana umur minimal yang didapatkan pada usia 14 tahun dan maksimal pada usia 69 tahun.

Berdasarkan variabel jenis kelamin, dari 62 penderita tersebut didapatkan penderita laki-laki lebih banyak dengan jumlah 32 penderita $(51,6 \%)$ sedangkan pada perempuan didapatkan 30 penderita $(48,4 \%)$.

Gambaran nilai rasio neutrofil limfosit pada penderita apendisitis akut didapatkan nilai median (IQR) 7,9\% (5,4\%), dimana rasio neutrofil limfosit minimal yang didapatkan pada nilai $2,0 \%$ dan maksimal pada nilai $27,4 \%$.

Berdasarkan diagnosis histopatologi anatomi dari 62 sampel penderita tersebut didapatkan $34(54,84 \%)$ penderita dengan hasil histopatologi apendisitis komplikata dan $28(45,16 \%)$ penderita dengan hasil histopatologi apendisitis non-komplikata. Berikut di bawah ini data analisa hasil pemeriksaan tersebut berupa tabel 1.

Kurva ROC (receiver operating characteristic) bertujuan untuk mengetahui kemampuan dari rasio neutrofil limfosit dalam mendiagnosis apendisitis komplikata dengan hasil histopatologi anatomi sebagai baku emas serta untuk mencari titik potong terbaik dari rasio neutrofil limfosit untuk 
dinyatakan positif negatif. Dari 62 penderita, didapatkan area under curve ROC 0,6229 dengan interval kepercayaan (CI) $95 \%$ dan titik potong terbaik dari rasio neutrofil limfosit pada apendisitis komplikata adalah >5 (gambar 1).

Tabel 1. Gambaran Karakteristik Subjek dan Variabel Penelitian

\begin{tabular}{lc}
\hline \multicolumn{1}{c}{ Variabel } & $\mathrm{n}=62$ \\
\hline Umur & \\
Median (IQR) & $23(15)$ \\
Min-Max & $14-69$ \\
Jenis kelamin & \\
Laki-laki & $32(51,6 \%)$ \\
Perempuan & $30(48,4 \%)$ \\
Rasio neutrofil / limfosit & \\
Median (IQR) & $7,9(5,4 \%)$ \\
Min-Max & $2,0-27,4$ \\
Diagnosis & \\
$\quad$ Non-komplikata & $28(45,2 \%)$ \\
Komplikata & $34(54,8 \%)$ \\
\hline
\end{tabular}

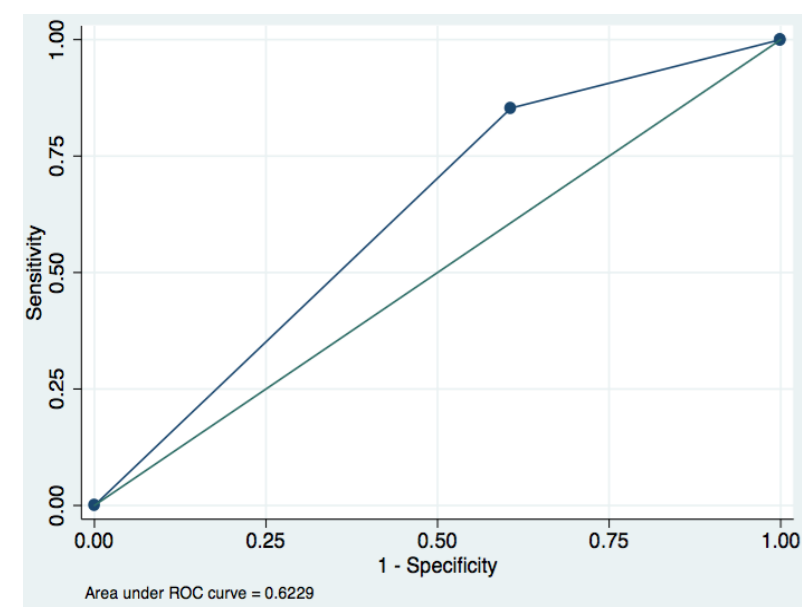

Gambar 1. Kurva ROC kemampuan rasio neutrofil limfosit dalam memprediksi apendisitis komplikata dengan hasil histopatologi anatomi sebagai baku emas

Pada uji validitas rasio neutrofil limfosit pada apendisitis komplikata bertujuan untuk mencari sensitivitas dan spesifisitas serta akurasi dengan menggunakan tabel $2 \times 2$ seperti dibawah ini (tabel 2).
Tabel 2. Uji Validitas Rasio Neutrofil Limfosit dan Hasil Histopatologi Sampel Penderita Apendisitis Akut di RSUP Sanglah Bulan Oktober-Desember Tahun 2015

\begin{tabular}{|c|c|c|c|}
\hline \multirow[b]{2}{*}{ RNL } & \multicolumn{2}{|c|}{ Histopatologi } & \multirow[b]{2}{*}{ Total } \\
\hline & $\begin{array}{l}\text { Apendisitis } \\
\text { Komplikata }\end{array}$ & $\begin{array}{l}\text { Apendisitis } \\
\text { Non- } \\
\text { Komplikata }\end{array}$ & \\
\hline$>5$ & 29 & 17 & 46 \\
\hline$\leq 5$ & 5 & 11 & 16 \\
\hline Total & 34 & 28 & 62 \\
\hline $\begin{array}{l}\text { Keterangan } \\
\text { Sensitivitas } \\
\text { Spesifisitas } \\
\text { Accuracy R } \\
\text { Positive Pr } \\
\text { Negative P }\end{array}$ & $\begin{array}{l}\rightarrow 29 /(29+5) \times 100 \\
\rightarrow 11 /(11+17) \times 10 \\
\text { ate } \rightarrow 29+11 /(29+ \\
\text { dictive Value } \rightarrow \\
\text { edictive Value } \rightarrow\end{array}$ & $\begin{array}{l}\%=85,3 \% \\
\%=39,3 \% \\
7+5+11) \times 100\end{array}$ & $\begin{array}{l}64,5 \% \\
63 \%\end{array}$ \\
\hline
\end{tabular}

\section{DISKUSI}

Pada hasil penelitian ini, ratio neutrofil limfosit dapat dijadikan tolak ukur atau parameter yang lebih baik, lebih cepat dan lebih murah untuk mendiagnosis apendisitis akut dibandingkan dengan menggunakan parameter yang sebelumnya seperti Alvarado Score dan USG abdomen. Kelebihan rasio neutrofil limfosit ini juga dapat membedakan apendisitis komplikata dan non-komplikata. Kelemahan Alvarado Score adalah bersifat subjektif dimana skor yang dihasilkan akan tergantung dari penilaian pemeriksa, tidak mudah digunakan untuk menilai pada pasien dengan gejala yang tidak khas, dan tidak bisa membedakan apendisitis komplikata dan non-komplikata. Sedangkan kelemahan USG abdomen yaitu bersifat subjektif, memiliki tingkat akurasi yang rendah, biaya lebih mahal, penilaian tergantung operator, dan tidak dapat membedakan apendisitis komplikata atau non-komplikata.

Berdasarkan hasil uji diagnostik rasio neutrofil limfosit pada apendisitis komplikata di RSUP Sanglah Denpasar, 
didapatkan nilai sensitivitas sebesar $85,3 \%$, nilai spesifisitas $39,3 \%$, dan tingkat akurasi $64,5 \%$, artinya bahwa hasil ini memiliki kemampuan mendeteksi dini diagnosis apendisitis komplikata. Hasil pada penelitian ini lebih tinggi dibandingkan penelitian dari Kahramanca yang mendapatkan hasil lebih rendah yaitu sensitivitas $70,8 \%$, spesifisitas $48,5 \%$ dan tingkat akurasi 52\%. Dari hasil yang berbeda ini, peneliti memiliki beberapa argumentasi mengapa penelitian ini mendapatkan hasil yang lebih tinggi, yaitu sampel yang dipilih adalah penderita yang benar-benar menderita apendisitis akut dengan tanda klinis yang jelas tanpa disertai penyakit infeksi lainnya. Keluhan terbanyak saat pasien datang adalah dengan nyeri perut kanan bawah yang khas disertai demam $\geq 38^{\circ} \mathrm{C}$ dan muntah, tampak dari laboratorium nilai neutrofil meningkat tajam dan nilai limfosit menurun dan saat dirasiokan nilainya tinggi sesuai dengan gejala klinis apendisitis komplikata. Terbukti pada hasil histopatologi anatomi bahwa semua penderita benar terdiagnosa paling banyak apendisitis komplikata $(54,8 \%)$ dan apendisitis non-komplikata $(45,2 \%)$. Berbeda dengan penelitian dari Kahramanca, sampel yang diambil adalah semua pasien yang telah menjalani operasi apendisektomi dengan diagnosis yang belum pasti penyakit tersebut murni apendisitis akut. Berdasarkan data tersebut, keluhan pasien yang datang paling banyak dengan nyeri perut dan tidak semua memiliki riwayat klinis yang khas menunjukkan apendisitis. ${ }^{4}$

Pada penelitian ini menggunakan desain studi kohort prospektif sehingga data yang didapatkan dari sampel lebih akurat. Berbeda dengan penelitian Kahramanca yang menggunakan desain penelitian retrospektif sehingga data yang didapatkan kurang akurat karena sampel yang diambil tidak ter-screening dengan baik saat awal. Terbukti pada hasil histopatologi, banyak pasien didapatkan dengan negative apendisitis serta didapatkan penderita ternyata disertai riwayat infeksi lain dalam perjalanan perawatan paska operasi. Peneliti menyimpulkan bahwa nilai sensitivitas, spesifisitas dan tingkat akurasi sangat dipengaruhi oleh cara pengambilan sampel yang benar dan desain penelitian.

Pada hasil penelitian ini didapatkan nilai cut of point rasio neutrofil limfosit pada apendisitis komplikata adalah $>5$ dan nonkomplikata $\leq 5$ berdasarkan kurva ROC dengan nilai area under curve ROC 0,6229 dan 95\% CI. Hasil ini termasuk tingkat sedang untuk screening diagnosa apendisitis komplikata dan non-komplikata melalui cut of point. Namun hasil ini lebih tinggi dibandingkan dengan penelitian sebelumnya Kahramanca, mendapatkan nilai area under curve ROC sebesar 0,609 dan $95 \%$ CI.

Peneliti menyadari bahwa pada hasil penelitian ini masih terdapat beberapa kelemahan dimana faktor-faktor risiko yang mempengaruhi nilai rasio neutrofil limfosit pada apendisitis komplikata tidak diteliti lebih lanjut sehingga mempengaruhi nilai validitas yang didapatkan pada penelitian ini. Faktor-faktor risiko tersebut berupa usia, batasan waktu pasien menderita apendisitis hingga dilakukan apendisektomi, batasan pengambilan sampel darah yang berhubungan dengan nilai neutrofil, dan follow up pasien setelah dilakukan operasi. Faktor-faktor ini juga berhubungan dengan tindakan approach apendisektomi (insisi Gridiron/ laparatomi), risiko morbiditas, mortalitas serta prognosis pasien apendisitis akut. Parameter RNL pada apendisitis komplikata akan lebih berguna apabila 
penelitian ini dilanjutkan sehingga kedepannya prognosis pasien apendisitis akan lebih baik.

\section{SIMPULAN}

Sensitifitas rasio neutrofil limfosit pada apendisitis komplikata adalah 85,3\%. Spesifitas rasio neutrofil limfosit pada apendisitis komplikata adalah 39,3\%. Akurasi rasio neutrofil limfosit pada apendisitis komplikata adalah $64,5 \%$. Nilai prediksi positif rasio neutrofil limfosit pada apendisitis komplikata adalah 63\%. Nilai prediksi negatif rasio neutrofil limfosit pada apendisitis komplikata adalah 68,8\%. Cut of point rasio neutrofil limfosit pada apendisitis komplikata adalah $>5$. Cut of point rasio neutrofil limfosit pada apendisitis non komplikata adalah $\leq 5$. Rasio neutrofil limfosit pada apendisitis akut ini dapat digunakan sebagai tolak ukur yang lebih baik untuk screening diagnosis apendisitis komplikata dan non komplikata dibandingkan dengan penilaian berdasarkan Alvarado score ataupun USG abdomen saja.

\section{DAFTAR PUSTAKA}

1. Froggatt P, Harmston C. Acute Appendicitis. In: Cosse, C., editor. Intestinal Surgery II. Oxford: Elsevier;2011.p.372-6.

2. Humes DJ, Simpson J. Clinical Presentation of Acute appendicitis: Clinical Sign-Laboratory FindingClinical Scores, Alvarado Score and Derivate Scores. In: Keyzer C, Gevenois PA, editors. Imaging of Acute Appendicitis in Adults and Children. United Kingdom: Springer;2011.p.1321.

3. Simpson J, Scholefield J. Acute Appendicitis. In: Scholefield J, editor.
Emergency Surgery. United Kingdom: Elsevier;2008.p.108-12.

4. Kahramanca S, Özgehan G, Şeker D, et al. Neutrophil-To-Lymphocyte Ratio As A Predictor Of Acute Appendicitis. Ulus Travma Acil Cerrahi Derg. 2014;20:1922.

5. Nasution A. "Hubungan Antara Jumlah Leukosit Dengan Apendisitis Akut Dan Apendisitis Perforasi" (tesis). Pontianak: RSU Dokter Soedarso;2011. 